Original Article

\title{
The reliability and validity of the Korean version of the Japanese orthopaedic association back pain evaluation questionnaire
}

\author{
Kyoung-Sim Jung, PhD, PT ${ }^{1) a}$, Jin-Hwa Jung, PhD, OT ${ }^{1) a}$, SAng-Hun JAng, PhD, PT ${ }^{2}$, \\ Hyun-Soo Bang, PhD, $\mathrm{PT}^{2)^{*}}$, TAe-Sung In, PhD, $\mathrm{PT}^{2)^{*}}$ \\ 1) Department of Occupational Therapy, Semyung University, Republic of Korea \\ 2) Department of Physical Therapy, Gimcheon University: 214 Daehak-ro, Gimcheon 39528, \\ Republic of Korea
}

\begin{abstract}
Purpose] The purpose of this study was to establish the reliability and validity of the Japanese Orthopaedic Association Back Pain Evaluation Questionnaire (JOABPEQ) translated into Korean for use with patients' low back pain. [Subjects and Methods] Sixty-two subjects with low back pain, 28 men and 34 women, participated in the study. Reliability was determined by using the intra class correlation coefficient and Cronbach's alpha for internal consistency. Validity was examined by correlating the JOABPEQ scores with the 36 item short form health survey (SF 36). [Results] Test-retest reliability was $0.75-0.83$. The criterion-related validity was established by comparison with the Korean version of the SF 36. [Conclusion] The Korean version of the JOABPEQ was shown to be a reliable and valid instrument for assessing low back pain.

Key words: Japanese Orthopaedic Association Back Pain Evaluation Questionnaire (JOABPEQ), Reliability, Validity
\end{abstract}

(This article was submitted Mar. 22, 2017, and was accepted Apr. 30, 2017)

\section{INTRODUCTION}

Low back pain is a common musculoskeletal disorder that more than $80 \%$ of the global population experiences at least once during their lifetime ${ }^{1,2)}$. In addition, low back pain is more frequently observed in the age group from the 40s to 80 s, and especially in females ${ }^{3)}$.

To restore normal function, patients with low back pain receive physical therapy ${ }^{4}$. Therefore, for effective treatment, a measurement tool to evaluate functions and monitor changes is needed ${ }^{5,6)}$.

Outcome measurement is important in decision making and evaluating the results, and is advantageous in continuous management of the patients ${ }^{7}$. In order to accurately evaluate low back pain, outcome measurement should include topics regarding pain, low back function, general health condition, work disability, and patient satisfaction ${ }^{8}$. While there are many scales that evaluate low back pain, there is no gold standard questionnaire on low back pain ${ }^{9}$.

The Japanese Orthopaedic Association Back Pain Evaluation Questionnaire (JOABPEQ) was developed from the original Japanese Orthopaedic Association (JOA) score, and is a disease specific outcome measure that the patients with low back pain can self-report ${ }^{10)}$. Most components are related to the International Classification of Functioning Disability and Health $(\mathrm{ICFDH})^{11)}$.

The JOABPEQ has been translated into various languages, such as Iranian ${ }^{12)}$, Thai ${ }^{13)}$, and Turkish ${ }^{9)}$, and has been determined to be highly reliable and valid. However, the reliability and validity of the Korean translation of the JOABPEQ have

\footnotetext{
*Corresponding authors. Hyun-Soo Bang (E-mail: 76044860@daum.net); Tae-Sung In (E-mail: in8386@naver.com)

${ }^{a}$ These two principal co-authors contributed equally to this study.

*These two corresponding authors contributed equally to this work.

(C2017 The Society of Physical Therapy Science. Published by IPEC Inc.

This is an open-access article distributed under the terms of the Creative Commons Attribution Non-Commercial No Derivatives (by-nc-nd) License. (CC-BY-NC-ND 4.0: https://creativecommons.org/licenses/by-nc-nd/4.0/)
} 
not yet been confirmed. Thus, the purpose of this study is to determine the reliability and validity of the Korean version of the JOABPEQ.

\section{SUBJECTS AND METHODS}

Subjects were 62 outpatients with low back disorder receiving physical therapy at C Orthopedic Clinic in Gyeonggii-do. The inclusion criterion was that the patients be diagnosed with lumbar spine disease. The exclusion criteria were the inability to read Korean or respond to the questionnaire, infection at the lumbar spine, tumor at lumbar vertebra or intradural tumor, traumatic lumbar instability, rheumatoid arthritis, recent surgery lumbar spine, or congenital spinal disorder. After the subjects were informed about the study, they agreed to participate and signed consent forms. The study was approved by the Institutional Review Board of Gachon University.

The JOABPEQ is a self-report questionnaire designed to evaluate low back disorder, dysfunction, and disabilities resulting from low back complaints. The questionnaire consists of 25 items in 5 subscales: low back pain, lumbar function, walking ability, mental health, and social function. The scores range from 0 to 100 and a low score indicates worse health status ${ }^{10)}$.

The forward- and back-translations of the JOABPEQ presented no major language problems for an expert committee including professors and language experts ${ }^{14}$.

To evaluate reliability, the test-retest method was used. The patients completed a Korean version of the JOABPEQ at first visit and again 2 weeks later. All tests were again collected by the same physiotherapist. The 14-day test-retest reliability was analyzed according to the intra class correlation coefficient $(2,1)$ as well as internal consistency with Cronbach's $\alpha$. Criterion-related validity was evaluated by correlating the 8 subscales of the Korean SF 36; General Health (GH), Physical Function (PF), Social Function (SF), Mental health (MH), Role Physical (RP), Role Emotional (RE), Bodily Pain (BP), and Vitality (VT).

\section{RESULTS}

The general characteristics of the subjects are shown in Table 1.

The ICC score was found to be $0.76,0.83,0.75,0.80$, and 0.79 for "low back pain," "lumbar function," "walking ability," "social life function." and "mental health" subscales respectively (Table 2).

The JOABPEQ parameter values showed significant correlations in all 8 subscales of the Korean version of the SF 36 (Table 3). Low back pain showed strong correlation with the RP, RE, and BP subscales. Lumbar function showed strong correlation with the PF subscale. Walking ability showed moderate correlation with the SF 36 subscales, except for VT. Social life function showed strong correlation with the PF subscale. Mental health showed strong correlation with the GH, $\mathrm{MH}$, and RE subscales.

\section{DISCUSSION}

In this study, the test-retest reliability of the Korean version of the JOABPEQ was determined to be high. The reliability of the Thai version was tested with a two-week interval because the symptoms did not show dramatic changes and difficulty in remembering the contents of the questionnaire ${ }^{13)}$. The subscales of low back pain, lumbar function, walking ability, social life function, and mental health all showed ICC $>0.7$, revealing high reliability. In this study, the reliability was also tested with a two-week interval, and all subscales showed high reliability with ICC $>0.7$.

In the Iranian version, internal consistency of the subscales was analyzed. Cronbach's $\alpha$ coefficient was acceptable, with the results ranging from $0.71-0.81^{12}$. In the Thai version, internal consistency of the subscales, excluding lumbar function, revealed to be acceptable with the score greater than 0.7 . For all the questions, internal consistency was very high, with a score of $0.866^{13)}$. In this study, the result of the internal consistency of the subscales was also acceptable like the Iranian and Thai versions. Cronbach's $\alpha$ coefficient was lower than 0.95 , confirming no item redundancy ${ }^{15}$.

In the Thai version, correlations in the 8 subscales of the SF 36 were analyzed to confirm the validity of the JOABPEQ. All subscales of the JOABPEQ showed significant positive correlation, which was explained as a result of the original JOABPEQ having been developed from the Rolland Morris Disability questionnaire and SF $36^{13)}$. Further, in the Turkish version, correlations with social function, mental health, bodily pain, and physical function from the subscales of the SF 36 were measured, confirming good to very good correlation. Excellent correlation was identified with the Oswestry Disability Index ${ }^{9}$. In this study, similar to the Thai version, correlations in the 8 subscales of the SF 36 were analyzed to evaluate the validity of the JOABPEQ. The results were similar to the Thai version with $\mathrm{r}=0.21-0.63$, showing significant positive correlation in all subscales.

In the Iranian version, responsiveness was analyzed to observe whether or not the JOABPEQ detects change before and after the intervention. In all the subscales, improvement was observed ${ }^{12)}$. The Thai version reported no floor and ceiling effect ${ }^{13)}$. In this study, a similar result to the aforementioned study was observed regarding the floor and ceiling effect, signifying that it consists of appropriate ranges to detect change ${ }^{16)}$

Cross-cultural adaptations of existing language questionnaires, by translating them into specific languages for each coun- 
Table 1. The demographic characteristics of study participants $(\mathrm{n}=62)$

\begin{tabular}{lc}
\hline & Mean \pm SD \\
\hline Characteristic & $62(28 / 34)$ \\
Gender, male/female & $42.5 \pm 16.6$ \\
Age (years) & $162.1 \pm 15.4$ \\
Height (cm) & $63.6 \pm 15.4$ \\
Weight (kg) & $20.1 \pm 10.2$ \\
Pain duration (months) & \\
The type of low back pain & 42 \\
Lumbar disc herniation & 7 \\
Lumbar canal stenosis & 2 \\
Spondylolisthesis & 3 \\
Scoliosis & 8 \\
Non-specific low back pain & \\
\hline
\end{tabular}

Table 2. Test-retest reliability for JOABPEQ

\begin{tabular}{lcc}
\hline & $\begin{array}{c}\text { Internal } \\
\text { consistency }(\alpha)\end{array}$ & ICC $(95 \% \mathrm{CI})$ \\
\hline Low back pain & 0.7 & $0.76(0.65-0.89)$ \\
Lumbar function & 0.68 & $0.83(0.72-0.93)$ \\
Walking ability & 0.74 & $0.75(0.61-0.87)$ \\
Social life function & 0.72 & $0.80(0.73-0.92)$ \\
Mental health & 0.78 & $0.79(0.67-0.90)$ \\
\hline
\end{tabular}

JOABPEQ: Japanese Orthopaedic Association Back Pain Evaluation Questionnaire; ICC: intraclass correlation coefficient.

Table 3. Pearson's correlation coefficients of the JOABPEQ with the SF-36

\begin{tabular}{lcccccccc}
\hline \multicolumn{1}{c}{ JOABPEQ } & GH & PF & SF & MH & RP & RE & BP & VT \\
\hline Low back pain & 0.42 & 0.40 & 0.47 & 0.27 & 0.54 & 0.63 & 0.62 & 0.48 \\
Lumbar function & 0.33 & 0.54 & 0.42 & 0.25 & 0.40 & 0.46 & 0.41 & 0.31 \\
Walking ability & 0.41 & 0.49 & 0.44 & 0.32 & 0.44 & 0.44 & 0.37 & 0.25 \\
Social life function & 0.30 & 0.51 & 0.37 & 0.21 & 0.47 & 0.43 & 0.40 & 0.40 \\
Mental health & 0.51 & 0.44 & 0.46 & 0.60 & 0.40 & 0.60 & 0.35 & 0.50 \\
\hline
\end{tabular}

All correlations are significant at the 0.05 level.

JOABPEQ: Japanese Orthopaedic Association Back Pain Evaluation Questionnaire; SF-36: 36-item short form health survey; GH: general health; PF: physical function; SF: social function; MH: mental health; RP: role physical; RE: role emotional; BP: bodily pain; VT: vitality

try, would enable comparisons of different populations and permit the exchange of information between the countries ${ }^{17)}$. Therefore, it is important that translations of the questionnaires adapted for the specific culture in order to deliver the same meaning. The JOABPEQ was translated into Korean to verify the reliability and validity. However, due to the small sample size, it is difficult to generalize the results. Further, responsiveness that detects change over time was not evaluated. In the future, a broader spectrum of patients with lower back disorder should be included to determine reliability; furthermore, correlation analysis with functional disability measurement tool related to various low back disorders other than quality of life are needed.

\section{ACKNOWLEDGEMENT}

This work was supported by the Gimcheon University Research Grant.

\section{REFERENCES}

1) Fardon DF, Milette PC, Combined Task Forces of the North American Spine Society, American Society of Spine Radiology, and American Society of Neuroradiology: Nomenclature and classification of lumbar disc pathology. Recommendations of the combined task forces of the North American Spine Society, American Society of Spine Radiology, and American Society of Neuroradiology. Spine, 2001, 26: E93-E113. [Medline] [CrossRef]

2) Becker A, Held H, Redaelli M, et al.: Low back pain in primary care: costs of care and prediction of future health care utilization. Spine, 2010, 35: 1714-1720. [Medline] [CrossRef]

3) Hoy D, Bain C, Williams G, et al.: A systematic review of the global prevalence of low back pain. Arthritis Rheum, 2012, 64: 2028-2037. [Medline] [CrossRef]

4) Davidson M, Keating JL: A comparison of five low back disability questionnaires: reliability and responsiveness. Phys Ther, 2002, 82: 8-24. [Medline] [CrossRef]

5) Cleland J, Gillani R, Bienen EJ, et al.: Assessing dimensionality and responsiveness of outcomes measures for patients with low back pain. Pain Pract, 2011, 11: 57-69. [Medline] [CrossRef]

6) Mannion AF, Porchet F, Kleinstück FS, et al.: The quality of spine surgery from the patient's perspective: part 2. Minimal clinically important difference for improvement and deterioration as measured with the Core Outcome Measures Index. Eur Spine J, 2009, 18: 374-379. [Medline] [CrossRef]

7) Fukui M, Chiba K, Kawakami M, et al.: Japanese Orthopaedic Association Back Pain Evaluation Questionnaire. Part 2. Verification of its reliability: The Subcommittee on Low Back Pain and Cervical Myelopathy Evaluation of the Clinical Outcome Committee of the Japanese Orthopaedic Association. J Orthop Sci, 2007, 12: 526-532. [Medline] [CrossRef] 
8) Bombardier C: Outcome assessments in the evaluation of treatment of spinal disorders: summary and general recommendations. Spine, 2000, 25: 3100-3103. [Medline] [CrossRef]

9) Gunaydin G, Hazar Kanik Z, Karabicak GO, et al.: Cross-cultural adaptation, reliability and validity of the Turkish version of the Japanese Orthopaedic Association Back Pain Evaluation Questionnaire. J Orthop Sci, 2016, 21: 295-298. [Medline] [CrossRef]

10) Fukui M, Chiba K, Kawakami M, et al.: Japanese Orthopaedic Association Back Pain Evaluation Questionnaire. Part 3. Validity study and establishment of the measurement scale: subcommittee on low back pain and cervical myelopathy evaluation of the clinical outcome committee of the Japanese orthopaedic association. J Orthop Sci, 2008, 13: 173-179. [Medline] [CrossRef]

11) Wang P, Zhang J, Liao W, et al.: Content comparison of questionnaires and scales used in low back pain based on the international classification of functioning, disability and health: a systematic review. Disabil Rehabil, 2012, 34: 1167-1177. [Medline] [CrossRef]

12) Azimi P, Shahzadi S, Montazeri A: The Japanese Orthopedic Association Back Pain Evaluation Questionnaire (JOABPEQ) for low back disorders: a validation study from Iran. J Orthop Sci, 2012, 17: 521-525. [Medline] [CrossRef]

13) Poosiripinyo T, Paholpak P, Jirarattanaphochai K, et al.: The Japanese Orthopedic Association Back Pain Evaluation Questionnaire (JOABPEQ): a validation of the reliability of the Thai version. J Orthop Sci, 2017, 22: 34-37. [Medline] [CrossRef]

14) Beaton DE, Bombardier C, Guillemin F, et al.: Guidelines for the process of cross-cultural adaptation of self-report measures. Spine, 2000, 25: 3186-3191. [Medline] [CrossRef]

15) Terwee CB, Bot SD, de Boer MR, et al.: Quality criteria were proposed for measurement properties of health status questionnaires. J Clin Epidemiol, 2007, 60: 34-42. [Medline] [CrossRef]

16) Gabel CP, Michener LA, Burkett B, et al.: The Upper Limb Functional Index: development and determination of reliability, validity, and responsiveness. J Hand Ther, 2006, 19: 328-348, quiz 349. [Medline] [CrossRef]

17) Costa LO, Maher CG, Latimer J, et al.: Psychometric characteristics of the Brazilian-Portuguese versions of the Functional Rating Index and the Roland Morris Disability Questionnaire. Spine, 2007, 32: 1902-1907. [Medline] [CrossRef] 